\title{
Artigos
}

\section{"O Jefferson falou que o meu cabelo é feio, é ruim": cabelo crespo e empoderamento de meninas negras na creche}

\begin{abstract}
Resumo: Discutimos neste artigo a questão do empoderamento das identidades infantis negras a partir da desconstrução dos estereótipos de beleza, considerando o cabelo crespo, a pele negra e as culturas infantis, no contexto de uma creche da Rede Municipal de São Paulo. A pesquisa evidencia como o toque e as formas de cuidar, pentear, enfeitar o cabelo retratam fortes mensagens para as meninas negras nas relações que elas estabelecem com as professoras e com outras crianças, para a construção positiva de suas identidades. Utilizamos como referência a Sociologia da Infância para investigar o ponto de vista das crianças, compreendendo-as como atores sociais portadoras de história e produtoras de cultura. As relações étnico-raciais e de gênero também se configuram como categorias de análise dos dados coletados. Os resultados indicam a relevância de investigações que abordem os diferentes aspectos das complexas e intrincadas relações entre gênero, raça e infâncias no cotidiano das creches.
\end{abstract}

Palavras-chave: Creche. Relações Étnico-Raciais. Relações de Gênero. Cabelo Crespo.

\section{"Jefferson said that my hair is ugly and bad": curly hair and empowerment of black girls in child day care}

Abstract: This article discusses the empowerment of black children's identities from the deconstruction of beauty stereotypes around curly hair, black skin, and childhood cultures, in the context of a government day care facility in the city of São Paulo, Brazil. The research highlights how the manners of touching, grooming, combing, and styling the children's hair carry strong messages for the black girls, who seek, in these relationships with teachers and with other children, elements for a positive construction of their identities. Sociology of Childhood is our reference to investigate the children's point of view, perceiving them as social actors, who are historical agents and culture producers. Racial and gender roles serve as categories for analyzing the collected data. The results reaffirm the importance of investigations that address the complex, intricate relationships between gender, race, and childhood in day care centers.

Keywords: Child Day Care. Race. Gender. Curly Hair.

\footnotetext{
1 Mestre em Educação (Psicologia da Educação) pela Pontifícia Universidade Católica de São Paulo. E-mail: rsilvia.lopes@gmail.com 2 Doutora pela Faculdade de Educação da USP. E-mail: waldetetristao@gmail.com
} 
bramowicz e Oliveira (2001) afirmam que as crianças desde muito pequenas passam por
processos de subjetivação. No caso das crianças negras, esse processo se dá apoiado na
imagem social do negro subalternizado ao branco, como fruto do racismo estrutural presente na sociedade brasileira. Nesse sentido, as crianças negras, por vezes, acabam se vendo fora de um padrão estético que elege as características eurocêntricas como as mais adequadas.

A partir dessas considerações, enquanto docentes e gestoras de instituições de educação da primeira infância, em especial na coordenação pedagógica, avaliamos que tal experiência contribuiu para que pudéssemos pautar nossos olhares na investigação de alguns processos de construção social que nos levaram a observar e analisar cenas na creche que envolvem meninas pequenas negras e a relação com seus cabelos.

Com o objetivo de reconhecer como os cabelos das meninas negras são percebidos por elas e pelas outras crianças na creche, fomos conduzidas às seguintes questões:

1. Como as meninas negras constroem suas identidades étnico-raciais nas relações sociais com meninos e meninas, a partir de seus cabelos crespos 3 ?

2. Quais são as mensagens que meninas negras recebem sobre seus corpos e cabelos?

3. Quais são as situações de afirmação, transgressão, empoderamento, resistência e ressignificação perceptíveis das meninas negras com os seus cabelos crespos nas relações com seus pares e com os adultos?

A investigação implicou numa escuta sensível de palavras e de corpos, dialogando com as culturas infantis (CORSARO, 2005, 2009 e 2011), na intenção de romper com o adultocentrismo (ROSEMBERG, 1976, 2011). Nesse sentido, o uso de metodologias ancoradas na Sociologia da Infância possibilitou a investigação com as crianças pequenas (FARIA; DEMARTINI; PRADO, 2002; SOARES, 2006; FARIA; FINCO, 2011; MARTINS FILHO; PRADO, 2011; SARMENTO, 2004, 2007, 2008) em busca de indícios de diferentes formas de interação entre elas e com os adultos.

As relações sociais de gênero (SCOTT, 1995; CRENSHAW, 2002; CARNEIRO, 2003 e FINCO, 2013) foram observadas no sentido de compreender o lugar da menina negra (ABRAMOWICZ; OLIVEIRA, 2011; FINCO; OLIVEIRA, 2011) em relação a outras crianças e adultos, nas situações do cotidiano na creche. Os estudos de gênero e feministas dão suporte para pensar nessas questões como

3 Chamaremos cabelo crespo aquele que, para além de ser parte do corpo individual e biológico, é representado como parte de corpo social, um tipo de linguagem que pode se constituir em veículo de expressão e símbolo de resistência cultural (GOMES, 2003, 2006 e 2012). 
construções sociais, tendo em vista a afirmação da heterogeneidade nas experiências das mulheres e crianças em busca de romper o sexismo e o racismo, bem como a compreensão das interseccionalidades (CRENSHAW, 2002) gênero, raça-etnia e classe social nas infâncias.

No que diz respeito à raça, Guimarães (1999) compreende o conceito enquanto uma construção social, portanto inexistente cientificamente, se pensado a partir do campo da biologia. Encontramos sustentação teórica para tratar de relações étnico-raciais (GOMES 2002a, 2002b, 2003 e 2012) nas investigações que apontam para a existência de diferentes interpretações que a sociedade brasileira e os atores sociais concebem a respeito das relações raciais, destacando o papel dos movimentos sociais, em particular dos movimentos negro e feminista, os quais redefinem e redimensionam as questões de gênero e racial na sociedade brasileira, dando-lhes uma dimensão e interpretação políticas.

Em Malachias (2005) encontramos reflexões que revelam particularidades do contexto educacional no qual estão presentes as relações raciais que envolvem adultos e crianças.

\section{"Nega do cabelo duro, qual é o pente que te penteia?"4 Da identidade negada à afirmação}

Ribeiro (2017) chama atenção para um dos equívocos recorrentes e relativos à confusão entre lugar de fala e representatividade. Em sua mais recente publicação, questiona quem tem direito à voz numa sociedade cuja norma é a branquitude, a masculinidade e a heterossexualidade.

O conceito de lugar de fala, na perspectiva da autora, é capaz de desestabilizar as normas vigentes por trazer a importância de se pensar no rompimento de uma voz única, com o objetivo de propiciar uma multiplicidade de vozes.

Desse modo, reconhecemos que as experiências das crianças negras podem ser teorizadas por pesquisadores e pesquisadoras não negros, porque todas as pessoas têm um lugar de fala. No entanto, compreendemos que a localização social de quem fala deve ser sempre explicitada.

Sendo assim, ressaltamos a coincidência que nos uniu e motivou a realização desta pesquisa: somos mulheres negras, professoras, gestoras em instituições de educação infantil e pesquisadoras das relações intrínsecas que envolvem a temática étnico-racial, gênero e infâncias, e é desse lugar, dessa localização social, que construímos nossa narrativa.

Por mais de três décadas atuamos em diferentes tipos de instituições de educação infantil, nas mais diversas regiões periféricas da cidade de São Paulo, conhecidas como Centros de Educação Infantil (CEI) ou Escolas Municipais de Educação Infantil (EMEI); e, ao nos encontrarmos, percebemos que as questões que nos mobilizaram profissionalmente estiveram também em nossas vidas de meninas e jovens embora, por algum tempo, ainda não estivessem elaboradas e compreendidas enquanto um conteúdo significativo no processo de construção/desconstrução da autoestima das crianças negras, em especial as

4 Malachias (2002, p. 35) lembra que já há quase sete décadas a marchinha de carnaval de autoria de David Nasser e Rubens Soares, 1942, "brinca" com a impossibilidade de pentear o cabelo de uma mulher negra, em razão de sua textura capilar. 
meninas, quando em diferentes espaços sociais e culturais, enquanto um corpo cuja estética é negada, estranhada ou afirmada (GOMES, 2002a, 2003).

Em nossa trajetória, compartilhamos experiências de desconforto relacionadas aos nossos cabelos, desde que fomos crianças e jovens nas décadas de 1970 e 1980, período no qual várias mães, avós e tias, incluindo as nossas, eram levadas a acreditar que deveriam alisar o cabelo de suas crianças, modificando-os quimicamente ou por calor. As intenções delas eram, como se diz, das melhores: desejavam que nossa imagem correspondesse a um padrão estético no qual a textura do cabelo crespo, socialmente considerado como ruim, fosse transformada em liso, para se tornar, enfim, um cabelo bom considerado como ideal, numa sociedade contraditoriamente composta, em grande parte, por uma população negra (GOMES, 2002a, 2002b).

Havia outras situações nas quais nossos cabelos não estavam alisados e, entretanto, eram mantidos constantemente presos ou trançados, o que também era motivo de chacota entre os nossos pares e grupos de socialização.

Hoje compreendemos que nossos familiares eram seduzidos pela crença de que precisávamos ter uma "boa aparência", o que nos permite entender que alisar os cabelos não significava necessariamente falta de consciência de pertencimento racial, mas sim uma crença de que, daquela forma, mulheres e homens seriam aceitos no mercado de trabalho, repleto de imigrantes e excludente aos negros em geral (MALACHIAS, 2005, p. 35). No caso das crianças, os adultos acreditavam que elas seriam aceitas se as marcas do corpo pudessem ser transformadas ou apagadas: cabelos alisados para as meninas e cabeça raspada ou com cabelo muito baixo, cortado à máquina, para os meninos.

Essas experiências e reflexões nos impulsionaram a investigar a atualidade das relações que são estabelecidas entre pares em contextos coletivos da creche, considerando a menina negra, seu cabelo crespo e sua pele negra.

Como nos alerta Gomes (2012), ao falarmos sobre corpo e cabelo, inevitavelmente nos aproximamos da discussão sobre identidade negra, que é vista levando-se em consideração um processo conflituoso e tenso, no qual o olhar do negro e da negra referente ao seu próprio corpo dialoga com um olhar externo em um processo de construção sociocultural.

Nesse sentido, o cabelo crespo e o corpo negro podem ser considerados expressões e suportes simbólicos da identidade negra no Brasil. Juntos, eles possibilitam a construção social, cultural, política e ideológica de uma expressão criada no seio da comunidade negra: a beleza negra. Por isso não podem ser considerados simplesmente como dados biológicos. (GOMES, 2012, p. 2)

Neste jogo de tensões, descobrimos semelhanças na construção de autoimagem e identidade, enquanto mulheres e negras que, por vezes, negavam seu pertencimento racial, vivendo a diferença como uma dor; e, em outras, buscavam espaços de afirmação, nos quais a cultura negra estivesse presente, numa constante tentativa de problematizar, desnaturalizar, aprender e, assim, descobrir e descortinar nossos corpos negados, reconhecendo-os e tomando posse deles como espaços de potência, saber e poder. 
Em meio a um processo de desconstrução do padrão e entendimento da construção da diferença, numa relação de oposição e poder (BRAH, 2006), vislumbramos em diferentes espaços e tempos a aceitação de nossos cabelos crespos, autorizado-os a permanecerem constantemente soltos, dialogando e ocupando espaços nos quais afirmamos uma estética e, na mesma medida, exercitamos o reconfigurar de corpos que foram construídos em negação e oposição aos padrões.

\section{O corpo negado: o corpo negro e a construção de identidade de meninos e meninas pequenos(as)}

Os Centros de Educação Infantil (CEI), na cidade de São Paulo, na maioria das vezes são conhecidos como creches - por vezes consideradas como instituições pobres para pobres (OLIVEIRA, 2006), provavelmente pela sua história e lenta transformação, de organizações de caridade para "guarda" das crianças pobres e negras (ROSEMBERG, 2011) para uma instituição social de amplo alcance reconhecida como espaço de cuidado e simultaneamente de educação e de afirmação de direitos das crianças como sujeitos sociais.

Enquanto coordenadoras pedagógicas, reconhecemos nesse espaço um instigante cotidiano que oferece oportunidade para a elaboração de inúmeras questões a respeito das relações que se estabelecem entre meninos e meninas negros(as) e brancos(as).

Desse modo, motivadas por nossa experiência, ficamos interessadas em investigar como, atualmente, as meninas negras percebem e constroem a imagem de seus corpos e formas de pertencimento étnico-racial; como constituem suas identidades de gênero no interior das instituições educativas; e como o cabelo crespo é visto e percebido por crianças pequenas brancas e negras nas interações com seus pares e com as professoras ${ }^{5}$ e demais educadoras na creche.

Quando pensamos nas instituições nas quais atuamos, no caso da creche, retomamos o termo "paparicação", anteriormente utilizado por Ariès (1981), para demarcar o surgimento de uma nova mentalidade em relação à criança, a partir do século XVIII, na Europa, especificamente no contexto francês, que possibilitou a construção da ideia moderna de infância descrita pelo historiador citado, e que, imediatamente, nos remete à reflexão sobre a distribuição desigual do afeto nos espaços educativos.

Oliveira e Abramowicz (2010) resgatam o termo "paparicação" para demonstrar situações nas quais se observa uma prática ou um tratamento diferenciado em relação às crianças, evidenciando que algumas ganham essa atenção diferenciada e outras não. As autoras denominam como situações de "paparicação" aquelas que revelam a diferença de tratamento das professoras em relação às crianças negras e brancas. Entre elas, citam:

1. Ganhar ou não o colo da professora;

2. Meninas preferidas pelas professoras eram caracterizadas como "princesas" ou como "filhas";

5 Tendo em vista o número significativo de professoras e educadoras que atuam na Educação Infantil, comprovado por inúmeras pesquisadoras da área, optamos por utilizar a denominação no feminino genérico quando nos referirmos a essas profissionais. 
3. No refeitório, sempre se presenciava as professoras beijando algumas crianças;

4. Rejeição do corpo negro para o toque, o abraço e o beijo;

5. Rejeição do corpo negro fora do modelo estético de beleza e saúde: o menino gordo era a causa do seu problema na coluna;

6. Rejeição do corpo negro suado.

De outro lado, as pesquisas que apresentam as crianças como sujeito oferecem pistas para a compreensão de que a engrenagem da instituição educacional precisa ser revista para funcionar adequadamente. Indicam também como podem ser potentes as ações da equipe gestora, das professoras e de demais funcionários(as) desde que se comprometam com a promoção da igualdade racial (OLIVEIRA, 2017) e de gênero na educação infantil, enquanto um projeto coletivo.

Até mesmo sob a forma de atendimento às exigências legais, é urgente que as instituições estejam comprometidas com a devida atenção à criança negra e com as interações que elas estabelecem com os diferentes sujeitos, desde a educação infantil, em especial no que diz respeito às questões relacionadas ao corpo e cabelo.

Estamos falando, sobretudo, a respeito da educação das relações étnico-raciais, que impõe aprendizagens entre brancos(as) e negros(as), trocas de conhecimentos, quebra de desconfianças, enfim, um projeto conjunto para construção de uma sociedade justa, igual, equânime (BRASIL, 2004). Na mesma medida, com o compromisso de romper estereótipos, reconhecemos a necessária educação para igualdade de gênero que acentue as diferentes formas de ser e de ocupar diversos espaços sociais.

No âmbito das investigações acadêmicas, Braga (2016), em sua dissertação de mestrado intitulada Solta o cabelo!: etnografia sobre o cabelo crespo como marcador de identidade étnico-racial entre crianças negras da educação infantil, utilizou como referencial teórico principal as ideias de Fanon (2008) sobre o racismo estrutural e Mauss (2003) para pensar nos sentidos que se localizam dentro da educação do corpo da criança negra na educação infantil, em uma creche na periferia do Rio de Janeiro. Desconstruindo o padrão de beleza centrado em apenas um grupo racial, a autora postula a importância de uma educação antirracista e pautada na diversidade.

Ainda para discutir as questões relacionadas ao cabelo da menina negra, Farias (2016) realizou uma pesquisa participativa numa unidade educacional paulistana, utilizando como referencial teórico a sociologia da infância por fornecer elementos relevantes para investigar como as crianças se relacionam entre seus pares e com as professoras. Também observou seus desenhos, por serem considerados como artefatos culturais da infância (GOBBI, 2002).

A forma como as crianças retratavam a si mesmas nos desenhos, além das conversas entre as crianças e as observações e registros da pesquisadora no caderno de campo nos momentos de brincadeira, expressavam tensão no que dizia respeito aos cabelos crespos e à pele negra, principalmente entre as meninas.

Os comentários pejorativos entre as crianças na brincadeira de salão de beleza - quando as meninas negras simulavam alisar seus cabelos com secador, utilizavam chapinhas e manifestavam o desejo 
de terem o cabelo pintado de loiro - revelavam o aprendizado de uma insatisfação com seus cabelos crespos.

Durante a pesquisa, Farias (2016) registrou frases como "cabelo crespo é ruim" e "odeio ter esse cabelo", como também relatou que se deparou com meninas cujos dedos ou couro cabeludo estavam queimados por uso de chapinha ou pelo uso de química para produzir a modificação da textura dos cabelos por escovas progressivas e alisamentos.

A autora revela ainda a preponderância da representação dos cabelos lisos nos desenhos das crianças, que eram considerados, principalmente pelas meninas, como os mais bonitos no universo de 192 desenhos elaborados por meninos e meninas, 92 representavam o cabelo liso.

Em nossa experiência pessoal e profissional, em especial no universo infantil, identificamos outras referências depreciativas ao corpo negro, relativas aos cabelos crespos, com as quais as crianças aprendem a nomeá-los: ruins, duros, rebeldes, bombril, palha de aço, o que nenhum pente poderia pentear. Sem dúvida, reconhecemos que é o desconforto que impulsiona algumas crianças negras a brincar ou fingir que seus cabelos são lisos, para eles serem socialmente reconhecidos como normais e bonitos.

As adjetivações pejorativas ao cabelo crespo ainda estão presentes no imaginário social e traduzem o preconceito e o racismo, por apontarem para uma estética de beleza e feiura na sociedade brasileira ancorada no passado escravista e eurocentrado (CARNEIRO, 2003 e GOMES, 2002a), fato que aponta para a necessidade de desconstrução desses estereótipos, de modo a desvelá-los (GOMES, 2002a e 2002b) para romper hierarquias e silenciamentos em busca de caminhos para construção e fortalecimento, uma vez que a ideologia racista e machista aprisiona diferentes subjetividades.

As relações de gênero e étnico-raciais expressam um complexo processo de constituição de identidades de meninas, especialmente quando são o corpo negro e o cabelo crespo que estão em oposição ao ideário de beleza. Nesse contexto, a manipulação do cabelo e por vezes o alisamento, ou a afirmação da beleza negra, são estratégias individuais desse percurso.

O cabelo do negro, visto como "ruim", é expressão do racismo e da desigualdade racial que recai sobre esse sujeito. Ver o cabelo do negro como "ruim" e do branco como "bom" expressa um conflito. Por isso, mudar o cabelo pode significar a tentativa do negro de sair do lugar da inferioridade ou a introjeção deste. Pode ainda representar um sentimento de autonomia, expresso nas formas ousadas e criativas de usar o cabelo.

(...) O tratamento dado ao cabelo pode ser considerado uma das maneiras de expressar essa tensão. A consciência ou o encobrimento desse conflito, vivido na estética do corpo negro, marca a vida e a trajetória dos sujeitos. Por isso, para o negro, a intervenção no cabelo e no corpo é mais do que uma questão de vaidade ou de tratamento estético. É identitária. (GOMES, 2002a, p. 3)

Reconhecer que os corpos negros sempre foram contestadores, como evidencia Gomes (2002a e 2002b), implica pensá-los não de forma essencializada, mas como espaços de cultura, de história, de relações sociais de poder, suportes nos quais a cor da pele e os cabelos são signos e ícones de identidades e como tais são temas que demandam investigações, pois geram impacto nas trajetórias desses sujeitos nos diversos segmentos etários e nos espaços educativos. 
Construir uma identidade negra positiva em uma sociedade que, historicamente, ensina ao negro, desde muito cedo, que para ser aceito é preciso negar-se a si mesmo, é um desafio enfrentado pelos negros brasileiros. (GOMES, 2003, p. 171)

Nesse sentido, negros e negras vão constituindo coletivamente e individualmente as suas identidades em oposição, negação e/ou resistência em relações assimétricas de poder (GOMES, 2002a e 2002b), num país marcado pela racialização das relações sociais (GUIMARÃES, 2003). O processo de construção de identidade racial se soma ao de gênero e classe, dentre outras identidades.

Como sujeitos sociais, é no âmbito da cultura e da história que definimos as identidades sociais (todas elas, e não apenas a identidade racial, mas também as identidades de gênero, sexuais, de nacionalidade, de classe etc.). Essas múltiplas e distintas identidades constituem os sujeitos, na medida em que estes são interpelados a partir de diferentes situações, instituições ou agrupamentos sociais. Reconhecer-se numa delas supõe, portanto, responder afirmativamente a uma interpelação e estabelecer um sentido de pertencimento a um grupo social de referência. Nesse processo, nada é simples ou estável, pois essas múltiplas identidades podem cobrar, ao mesmo tempo, lealdades distintas, divergentes, ou até contraditórias. Somos, então, sujeitos de muitas identidades e essas múltiplas identidades sociais podem ser, também, provisoriamente atraentes, parecendo-nos, depois, descartáveis; elas podem ser, então, rejeitadas e abandonadas. Somos, desse modo, sujeitos de identidades transitórias e contingentes. (GOMES, 2003, p. 171)

Trazer esta temática muitas vezes silenciada nas instituições educativas foi se tornando cada vez mais foco das inquietações que impulsionaram esta investigação, pensando-se nas crianças negras e nos seus processos de construção de identidade, em especial as meninas negras e seus cabelos crespos na creche.

\section{Sociologia da infância: mais uma lente para olhar a realidade investigada}

Apostando na sociologia da infância como aporte teórico, nossa intenção é investigar o ponto de vista das crianças, em contextos coletivos de educação infantil, tendo como premissa que a infância é uma construção histórica e social.

Considerada como um campo em construção, a sociologia da infância tem como convergência a tarefa de, a partir do fenômeno social da infância, compreender a sociedade (SARMENTO, 2007, 2008), demandando que se pense nas várias formas de ser criança e de viver a infância, considerando-se os diversos contextos.

Esse campo postula a(s) infância(s) como categoria(s) geracional(is) e as crianças como atores sociais que constroem as culturas infantis na interação com seus pares e com as demais categorias geracionais socialmente construídas (SARMENTO, 2004, 2007, 2008, 2009 e CORSARO, 2011). Essa direção contrapõe-se à ideia de pensar numa criança a-histórica, como antes proposto no campo das ciências, em especial da psicologia e da medicina, renovando também o campo da sociologia no que se refere ao processo de socialização, na perspectiva durkhemiana (SARMENTO, 2008, 2009 e CORSARO, 2011). 
A infância enquanto categoria social é homogênea e ao mesmo tempo heterogênea no que se refere às categorias geracionais e demais marcadores sociais, como gênero, raça, etnia e classe social (SARMENTO, 2008). Pensar as relações de gênero a partir da interseccionalidade (CRENSHAW, 2002), articulando-as com os demais marcadores sociais, indica eixos de subordinação imbricados nas relações de poder que "criam desigualdades básicas que estruturam as posições relativas de mulheres, raças, etnias, classes e outras" (CRENSHAW, 2002, p. 7). Considerar estas questões é fundamental para pensar nas experiências das meninas negras na creche e as formas como elas constroem culturas com seus pares e nas relações com as adultas.

Em se tratando das culturas infantis, consideramos aquelas produzidas pelas crianças por se caracterizarem enquanto uma dimensão primeira do reconhecimento de que elas constroem significados autônomos, expressos a partir de suas próprias referências (SARMENTO, 2004).

As crianças produzem uma série de culturas locais que se integram e contribuem para culturas mais amplas de outras crianças e adultos a cujo contexto estão integradas. Esses processos variam ao longo do tempo e entre culturas, e a documentação e a compreensão dessas variantes devem ser um tema central na nova sociologia da infância. (CORSARO, 2011, p. 127)

Uma segunda dimensão se refere aos elementos de representação não subordinados aos princípios da lógica formal, adulta, mas compreensíveis para as crianças, dimensão que permite compreender que os elementos constitutivos das culturas infantis têm especificidades, tais como os jogos, os brinquedos, as brincadeiras, os gestos, os desenhos (SARMENTO, 2004), que permitem reconhecê-los como artefatos culturais infantis (GOBBI, 2002).

Em se tratando do processo de socialização das crianças, Corsaro (2011) evidencia que ele não pode ser reduzido a adaptação ou internalização da cultura dos adultos, pois envolve simultaneamente um processo de apropriação, reinvenção e reprodução, no qual põe em destaque a atividade das crianças com seus coetâneos (cultura de pares) e com os adultos, trazendo o conceito de reprodução interpretativa.

O que é fundamental para esta visão de socialização é o reconhecimento de como as crianças negociam, compartilham e criam cultura com adultos e entre si (Corsaro, 1992; Jenks e Prout, 1998). No entanto, dizer que uma perspectiva sociológica de socialização destaca a importância de processos coletivos e conjuntos não é suficiente para a construção de uma nova sociologia da infância (...) Em vez disso, proponho a noção de reprodução interpretativa. O termo interpretativo abrange os aspectos inovadores e criativos da participação infantil na sociedade (...) as crianças criam e participam de suas próprias e exclusivas culturas de pares quando selecionam ou se apropriam criativamente de informações do mundo adulto para lidar com suas próprias e exclusivas preocupações. $\mathrm{O}$ termo reprodução inclui a ideia de que as crianças não se limitam a internalizar a sociedade e a cultura, mas contribuem ativamente para a produção e mudança culturais. O termo também sugere que as crianças estão, por sua própria participação na sociedade, restritas pela estrutura social existente e pela reprodução social. Ou seja, a criança e sua infância são afetadas pela sociedade e culturas que integram. Essas sociedades e culturas foram, por sua vez, moldadas e afetadas por processos de mudanças históricas. (CORSARO, 2011, pp. 31 32)

Faria e Finco (2011), tendo como referência as contribuições da sociologia da infância, defendem estudos a partir de uma perspectiva pós-colonialista, ao darem visibilidade a uma criança concreta, não homogeneizada, questionando quem são as crianças brasileiras, o que elas têm em comum e o que as 
distingue umas das outras. Nesse sentido, torna-se fundamental pensar nas crianças, desde bebês, como atores sociais, participantes ativos, que manifestam e expressam de forma muito peculiar aspectos significativos da sua cultura por meio das suas brincadeiras, do seu corpo e de suas percepções sobre o que é ser menina e menino. Trata-se de identidades que se constituem em relação com os seus pares e com os adultos em processos que por vezes afirmam os padrões binários de gênero construídos socialmente, e por vezes transgridem tais padrões e normas, com suas formas de agir e lógicas diferentes dos adultos, borrando fronteiras de gênero (FINCO, 2010 e 2013).

Nessa perspectiva, gênero enquanto uma construção histórica e social é elemento constitutivo das relações sociais baseadas nas diferenças percebidas entre os sexos, uma forma primária de dar significados às relações de poder (SCOTT, 1995). O controle e acesso diferenciados aos recursos materiais e simbólicos, assim como a questão de produção e reprodução do trabalho, são também indicadores da forma como se estabelece a distribuição de poder numa sociedade.

Assim, as relações de gênero são plurais, com variáveis geracionais, raciais, étnicas e territoriais, as quais permitem compreender práticas diferenciadas entre homens e mulheres, enquanto construções sociais que estabelecem relação de poder - e, portanto, assimétrica e hierárquica. Tais evidências indicam a urgência em combater o sexismo e racismo que estruturam a nossa sociedade (CARNEIRO, 2003), por serem demandas que se impuseram tanto nos feminismos quanto na produção acadêmica. Cabe aqui o instigante conceito de interseccionalidades (CRENSHAW, 2002) de gênero, raça e classe, por fornecer ferramentas metodológicas para investigar também as infâncias.

Desnaturalizar papéis e estereótipos sociais do masculino e feminino deve ser mais uma das demandas que revestem o olhar com as crianças e as suas formas de viverem a infância, uma vez que esses estereótipos passam também a ser reproduzidos nas atividades diárias, nos corpos em suas gestualidades: "o modo como estão sendo educados pode contribuir para tornarem-se mais completos ou, por outro lado, para limitar suas iniciativas e suas aspirações" (FINCO, 2013, p. 174).

As preferências e os comportamentos de meninas e meninos não são meras características oriundas do corpo biológico, são construções sociais e históricas. Ao buscar suas causas, encontraremos suas origens em reações automáticas, em pequenos gestos cotidianos - cujos motivos e objetivos nos escapam - que repetimos sem ter consciência de seu significado, porque os interiorizamos no processo educacional. São preconceitos que não resistem à razão nem aos novos tempos e que continuamos a considerar verdades intocáveis, nos costumes e nas regras inflexíveis. "E todo preconceito impede a autonomia do ser humano, ou seja, diminui sua liberdade relativa diante do ato da escolha, ao deformar e, consequentemente, estreitar a margem real do indivíduo." (HELLER, 1992, p. 59).

Diante das opressões que as crianças sofrem, meninos e meninas podem deixar de exercitar habilidades mais amplas, deixar de experimentar, de inventar e de criar. (FINCO, 2013, p. 174)

Contrapor-se a essa lógica significa pensar em diferentes contextos e nas relações sociais neles estabelecidas, sobretudo na forma como as crianças vivem as suas infâncias nas instituições de educação infantil - dentre elas a creche, que se configura como um dos espaços de produção e circulação de culturas 
infantis onde, por meio das brincadeiras e das interações, e nos seus traçados e formas de expressão, as crianças atribuem sentido e ressignificam aspectos do cotidiano.

Tais conteúdos instigam a reflexão sobre "como" as meninas negras se reconhecem e são reconhecidas na creche e como se dão as relações étnico-raciais de gênero no cotidiano dessa instituição educativa. Motivam ainda a busca de indícios que permitam identificar a forma como se configura, nesse espaço, a possibilidade de reprodução e/ou ruptura com estereótipos presentes na sociedade em que elas vivem.

Assim, a pesquisa que motivou este artigo procura abordar as questões de gênero e raça a partir dos indícios fornecidos pelas falas, choros, corporeidades, nas diversas formas de interação e brincadeiras, buscando compreender de que modo essas relações são reproduzidas ou alteradas nos corpos históricos e sociais, constituindo-se numa relação de tensão e de poder onde o cabelo é considerado como ícone de construção de identidade da menina negra.

Gomes (2012) destaca o corpo negro e o cabelo crespo enquanto símbolos da identidade negra porque são aspectos tomados pela cultura na construção da representação social e da beleza do negro(a) na sociedade brasileira:

(...) cabelo não é um elemento neutro no conjunto corporal. Ele é maleável, visível, possível de alterações e foi transformado, pela cultura, em uma marca de pertencimento étnico/racial. No caso dos negros, o cabelo crespo é visto como um sinal diacrítico que imprime a marca da negritude nos corpos. Ele é mais um elemento que compõe o complexo processo identitário. Dessa forma, podemos afirmar que a identidade negra, enquanto uma construção social, é materializada, corporificada. Nas múltiplas possibilidades de análise que o corpo negro nos oferece, o trato do cabelo é aquela que se apresenta como a síntese do complexo e fragmentado processo de construção da identidade negra. (GOMES, 2002a, p. 7)

Configura-se então como desafio investigar o complexo e intrincado processo de constituição de identidades das meninas negras na creche numa sociedade etnocêntrica e eurocêntrica.

\section{A pesquisa na creche, o contexto}

Desenvolvemos uma pesquisa qualitativa e etnográfica com crianças (CORSARO, 2005, 2011) em um Centro de Educação Infantil (CEI) localizado na região norte da cidade de São Paulo, numa região periférica, com consideráveis índices de vulnerabilidade social.

$\mathrm{Na}$ ocasião da pesquisa, o CEI em questão funcionava no período das 8 às 18 horas e atendia crianças na faixa etária de 2 anos até 3 anos e 11 meses.

Por exigência legal, todas as profissionais que atendem as crianças são formadas no curso de Pedagogia, e ainda há algumas delas que receberam a formação em serviço oferecida pela Prefeitura de São Paulo, conhecida como ADI Magistério, no período de transição das creches da Secretaria de Assistência Social para a Secretaria Municipal de Educação (OLIVEIRA, 2006).

A equipe responsável pelo funcionamento do CEI era composta por 33 funcionários, sendo 30 mulheres, que atuavam nas equipes gestora (diretora da escola, assistente de direção e coordenadora 
pedagógica), docente e de apoio, das quais oito declararam-se como mulheres negras. Destas oito mulheres negras, nas diversas funções, apenas três mantinham os cabelos crespos; as demais mantinham seus cabelos quimicamente modificados.

Eram três educadores homens que atuavam como auxiliares técnicos de educação (ATE) e que eram também funcionários públicos. Dentre os ATEs, apenas uma educadora executava as tarefas administrativas junto à gestão. Os demais, de acordo com a proposta pedagógica da instituição, eram responsáveis pelo suporte e acompanhamento das crianças ao longo do dia. Os serviços de limpeza e cozinha eram realizados por trabalhadores(as) de empresas terceirizadas.

Ao que parece, o significativo número de mulheres negras atuando nas creches ainda remete às conquistas do Movimento de Luta por Creches que, para Oliveira (2006), se constituiu numa possibilidade para que as mulheres negras escapassem do destino que historicamente estava posto a elas: as tarefas braçais e sexuais e o trabalho como empregadas domésticas.

A investigação foi realizada nos meses de março a dezembro de 2016 (CHAVES, 2017) ${ }^{6}$. Realizamos a observação participante das crianças e as devidas anotações em caderno de campo. O fato de uma das pesquisadoras ter acesso ao campo investigado foi um aspecto facilitador, embora tenha demandado, ao mesmo tempo, estratégias para garantir aproximação brincante de forma a nos consolidar como adultas atipicas entre as crianças, como define Corsaro $(2005,2011)$.

Compreendemos que, quando se trata de pesquisas realizadas com crianças pequenas, na perspectiva de seu pertencimento e de sua inserção, a alteridade e a dimensão ética devem nortear as relações entre adultos e crianças, tendo em vista reconhecer as culturas infantis como modo específico, geracionalmente construído, de interpretação e de representação do mundo, as quais se manifestam na exploração autônoma das crianças, nas escolhas dos temas e dos procedimentos metodológicos (FARIA; DEMARTINI; PRADO, 2002; SOARES, 2006; FARIA; FINCO, 2011; MARTINS FILHO; PRADO, 2011; CERISARA, 2004).

Nosso compromisso como pesquisadoras era o de educar nossos olhos para o constante estranhamento (FARIA; FINCO, 2010) e possibilitar escutas que dialogassem com a polifonia das culturas infantis no cotidiano das instituições. Nesse sentido, outro importante desafio na pesquisa se impôs: seríamos capazes de desenvolver uma escuta para além das palavras, uma escuta que evocasse também as gestualidades, para dar visibilidade às diferentes marcas sociais e corporeidades das crianças no cotidiano da educação infantil?

O ponto de partida é a observação das crianças: o que buscam saber sobre o mundo à sua volta, quais suas preocupações e que perguntas estão fazendo num dado momento? Afinal: para onde está direcionada a curiosidade das crianças? É necessário, pois, olhar a criança, as diferentes crianças, os movimentos do grupo. É urgente ouvir suas perguntas: no choro, no balbucio, no gesto, na palavra, na ação. A escuta é disponibilidade ao outro e a tudo que ele tem a dizer. E mais: a escuta torna-se, hoje, o verbo mais importante (...) (OSTETTO, 2000, p. 194)

6 Estes dados foram utilizados originalmente para compor artigo apresentado no Seminário "Fazendo Gênero 2017" (Simpósio Temático 34). 
Compartilhamos intensamente nossos registros e impressões, o que em muito favoreceu nosso processo de análise. Dentre as cenas registradas para realização deste artigo, selecionamos uma que denominamos: "Os cabelos bonitos de Alana". Como procedimento ético, utilizamos nomes fictícios de forma a preservar as identidades das crianças envolvidas.

\section{Cena analisada: "Os cabelos bonitos de Alana"}

Era o final da hora do sono, na sala do Mini Grupo I. Nesse momento, as 12 crianças (7 meninos e 5 meninas) eram cuidadosamente observadas pela professora e por uma outra educadora. No entanto, em determinado momento, Alana, com 3 anos, acorda segurando o elástico que prendia o seu cabelo crespo. Sem falar nada, sai da sua sala, atravessa o refeitório e vai ao encontro de uma das pesquisadoras. O seu cabelo estava dividido em 3 "birotes" pequenos que se soltaram enquanto dormia. A professora chamou por ela e perguntou onde ela iria, sem obter resposta.

Alana chegou se aconchegando no colo de uma das pesquisadoras, sem falar nada; mas, chorando, pôs o elástico nas mãos dela, que logo perguntou o que tinha acontecido. Ela se aconchegou mais no colo, olhou para a pesquisadora e disse: "O Jefferson falou que meu cabelo é feio, é ruim", e começou a chorar mais intensamente. A pesquisadora a abraçou e começou a conversar com ela: "Alana, seu cabelo é bonito, você é bonita! Seu cabelo é diferente do dele e é igual ao meu". Ela olhava atentamente para o cabelo crespo da pesquisadora e o manuseava por todo o seu comprimento enquanto conversavam.

Nessa interação, Alana ficou olhando atentamente para o cabelo da pesquisadora, que por sua vez ficou manuseando o cabelo da Alana, perguntando se ela gostaria que deixasse uma parte do cabelo solto. Alana concordou e quis deixar a maior parte do seu cabelo solto, mudando o penteado com que vinha diariamente. A pesquisadora o tempo todo usou o espelho e foi mostrando o penteado que pretendia fazer nela. Os olhos de Alana foram ficando brilhantes enquanto a pesquisadora fazia o penteado nela, sempre perguntando se poderia utilizar um creme de pentear. Ela ficou atenta e sorridente, mexia no cabelo da pesquisadora, sentia a textura, enquanto olhava o penteado que surgia no seu cabelo.

A pesquisadora perguntava se ela queria que fosse feito um penteado diferente no cabelo crespo da Alana, deixando solta a parte de trás; ela balançava a cabeça dizendo que sim. Ficou sorridente quando olhava para sua imagem refletida nos dois espelhos utilizados pela pesquisadora: seus cabelos, que constantemente estavam presos, estavam soltos!

O efeito de se olhar no espelho, notar o próprio cabelo solto, em um formato diferente, e o fato de ter como referência a figura de uma mulher negra (pesquisadora) com cabelos crespos não alisados, com a qual interagiu muito ao longo do ano, fizeram toda a diferença. Ao final, as duas foram até a sala de mãos dadas e a menina voltou alegre ao grupo.

Quando ela entrou, a professora elogiou o cabelo dela que estava muito bonito, e a menina contou o que o Jefferson havia dito. A professora falou para o Jefferson pedir desculpa. Contrariado, ele pediu rapidamente desculpas a Alana e voltou a brincar com a massinha de modelar juntamente com o 
amigo Marcos. Alana foi em direção ao Jefferson e falou enfaticamente que o cabelo dela era bonito. Depois, virou-se para outro lado e, sentada perto de outra criança, começou a brincar com massa de modelar, distribuída pela professora.

Segundo Nilma Lino Gomes (2012), embora atualmente os currículos oficiais aos poucos incorporem leituras críticas sobre a situação do negro, e embora alguns docentes se empenhem no trabalho com a questão racial no ambiente escolar, o cabelo e os demais sinais diacríticos ainda são usados como critérios para discriminar as crianças negras.

A questão do cabelo crespo como expressão da estética negra ainda não é considerada um tema relevante no cuidado e educação de bebês e crianças pequenas, o que contribui para a exclusão das estéticas e culturas negras e sobretudo da identidade negra, como se pode observar no caso de Alana.

Atenta ao cotidiano educativo com as crianças pequenas, Malachias (2005) relata que, ao dar banho e pentear as crianças, muitas são identificadas pelas profissionais da educação infantil, em especial, como cabeças de "fuá", provavelmente porque, para elas, essa palavra define o embaraço dos cabelos despenteados. A autora chama atenção para a palavra "fuá" e seus inúmeros significados: intriga, fuxico, caspa, doença de pele produzida por piolhos, pó finíssimo que se desprende da pele arranhada... Esses significados não são positivos e reforçam de maneira pejorativa a ideia de que crianças negras têm "cabelo ruim", conforme foi proferido por Jefferson.

Outro chamamento preconceituoso utilizado por agentes escolares, educadores e até mesmo pelos próprios familiares das crianças é "cabelo pixaim". A definição deprecia o cabelo crespo, "encarapinhado" (tipo carapinha), característico dos negros, pelo fato de não ser naturalmente liso. Porém, essas pessoas desconhecem que, no Brasil, o emprego desses termos pode ser considerado racista e, portanto, criminoso. (MALACHIAS, 2005, p. 12)

Em outro contexto, duas professoras observadas por Malachias (2005) afirmaram não existir preconceito racial nas escolas. Entretanto, a pesquisadora observou que nenhumas delas acariciava as cabeças de "fuá", ou seja, não passam suas mãos em "cabelo ruim", não sendo capazes, portanto, de perceber que tais atitudes eram sinais subjetivos e não menos relevantes de que não estavam tratando as crianças com igualdade.

Farias (2016), na unidade educacional que pesquisou, se deparou com falas negando o cabelo crespo e com brincadeiras que afirmavam o cabelo liso como padrão de beleza, o que afetava principalmente as meninas negras. Dentre as cenas observadas no cotidiano, também caberia destacar a de uma criança que tinha soltado o cabelo crespo e foi censurada pelas demais meninas. Os olhares de reprovação das outras professoras e equipe de limpeza sinalizaram o desconforto diante do cabelo crespo solto, tal como observado na cena de Alana.

Em contrapartida, Farias destacou a intervenção da professora e o engajamento dela tendo em vista a temática étnico-racial, mas as falas de demais docentes negando o racismo ao afirmar que as crianças pequenas não têm maldade evidenciaram que silenciamentos também se fizeram presentes na equipe com relação à questão étnico-racial. 
Braga (2016) destacou na sua investigação o processo de constituição de meninos e meninas negras na educação infantil numa sociedade marcada pela ótica colonialista que estigmatiza o negro e a negra, pondo-os em posição de subalternidade. As formas depreciativas de designar o cabelo crespo, como marca da rejeição dos sinais corporais que denotam o pertencimento étnico-racial, afetam a autoestima das crianças pequenas negras.

Tal como destaca Gomes (2012), os efeitos dessas experiências nas trajetórias das crianças nas instituições educativas são nocivos para autoestima quando o cabelo e a questão da beleza são pensados a partir da ótica eurocêntrica e colonizadora. Outro aspecto que se destaca é o silenciamento dessas questões no cotidiano: as professoras entrevistadas não apontavam o racismo como questão que permeava o cotidiano com bebês e crianças pequenas, mas nem todas as crianças são atendidas igualmente; a espera de bebês negros e negras nas ações de cuidado foi relatada na sua investigação.

Observamos situações semelhantes no contexto desta investigação, e próximas àquelas apontadas nas pesquisas mencionadas, a destacar o desconforto docente para abordar a temática da diversidade étnico-racial em busca de uma pedagogia antirracista, da mesma maneira que pudemos observar um olhar naturalizado referente às relações sociais de gênero.

Quando olhamos para gestualidades que esbarram nas fronteiras de gênero (FINCO, 2010), observamos no âmbito docente o desconforto com meninos que usavam panos imitando cabelos longos, o que não acontecia com as meninas, mesmo as negras, ao simularem os cabelos lisos com panos, negando seus próprios cabelos. Outro desconforto se evidenciava no uso de fantasias como de borboletas ou fadas pelos meninos: o uso era permitido, mas os olhares e risos das adultas poderiam funcionar como censura ao que fugia do padrão de masculinidade hegemônico (CONNELL, 2013). As meninas eram encorajadas quando utilizavam essas fantasias e formas de adornar os cabelos tendo como referência o modelo eurocêntrico de princesas, visto como norma para meninas negras e brancas.

Os cabelos das meninas eram penteados diariamente ao final do dia antes de irem para casa, ou durante o dia quando solicitado pela criança. Os banhos eram dados somente quando houvesse alguma situação de troca na qual isso se fizesse necessário para o conforto da criança, caso contrário eram dados em casa. Na situação de pentear o cabelo, nos chamou atenção que, embora todas fossem penteadas, as meninas com cabelo crespo ficavam geralmente por último. Estas observações se somam à cena relatada, apontando a necessidade de um olhar para o currículo das instituições voltadas à primeira infância no qual as diferenças sejam pautadas, tendo em vista as várias formas de serem meninas e meninos e viverem as infâncias, rompendo estereótipos, considerando os efeitos nocivos do racismo e sexismo que aprisionam as crianças brancas, negras, indígenas.

Outra situação que vale relatar é a de uma brincadeira que as professoras fizeram com as crianças, denominada de "oficina de salão de beleza". O que observamos foi a ornamentação das crianças a partir de um determinado padrão imposto por elas: os cabelos dos meninos eram arrumados com spray colorido e mousse e os das meninas, com presilhas coloridas compradas pelas próprias professoras. 
Nesse cenário, a dificuldade de ornamentar o cabelo de Alana se fez presente para a professora com cabelo liso: a menina foi deixada para o final, quando então a professora pediu ajuda da profissional da limpeza que imediatamente se ofereceu para penteá-la, por ter uma filha com cabelo crespo. Depois de molhar, passar creme de pentear e esticar os cabelos da menina, os adereços e presilhas foram utilizados, mas para amarrar e recompor os três "birotes" em dois rabos de cavalo esticando o cabelo. Para essa atividade havia um espelho grande, pentes, escovas e vários adereços para o cabelo. Ao final todos e todas foram para um baile com adultos e crianças.

Essas situações forneceram alguns indícios para pensar a invisibilidade do cabelo crespo, sua negação, e o quanto tais experiências afetam principalmente as meninas negras, uma vez que a constituição de identidades se dá em relação e se pauta no olhar que o outro tem sobre o sujeito e no olhar que este tem sobre si.

Nesse sentido, podemos afirmar que estamos diante do racismo "também referido como sendo um corpo de atitudes, preferências e gostos instruídos pela ideia de raça e superioridade racial, seja no plano moral, estético, físico ou intelectual" (GUIMARÃES, 2004, p. 17), que se evidencia no interior das instituições educativas ao se colocar uma estética como padrão.

Estamos diante de um cenário no qual o menino Jefferson estigmatiza os cabelos crespos como ruins e feios, afirmando com seus atos as desigualdades sociais presentes numa sociedade com os ranços da colonização e da escravidão negra, na qual o cabelo crespo e a pele se configuram como fenótipos que balizam as relações sociais num país pluriétnico. Trata-se de uma experiência de construção de um imaginário cuja valoração positiva é para a matriz europeia, desconsiderando a africana e a indígena.

Refletindo sobre a postura da professora, acreditamos que o silenciamento diante destas questões implica em fortalecer um ideário racista que afeta tanto os Jeffersons como as Alanas nas creches.

Outro aspecto que vale destacar na observação foi a oficina de salão de beleza como um exercício de “dicotomização de gênero"nas ações de cuidado e educação, nas quais se fazem presentes a colonização dos corpos, que naturaliza e universaliza padrões e estéticas aceitáveis ou passíveis (FINCO, 2015), ao mesmo tempo em quesilencia o racismo estrutural e aprisiona tais corpos numa lógica binária socialmente construída, hierarquizando-os. Estes indícios trazem à tona a reflexão necessária sobre corpo, gênero, infância e as relações sociais e culturais e de poder que estão imbricadas na constituição de identidades pelas crianças, tal como proposto pela autora:

O corpo, seus movimentos, gestos, posturas, ritmos, expressões, linguagens são construções sociais que acontecem nas relações entre as crianças, entre estas e os adultos, de acordo com cada sociedade e cultura. Do corpo nascem e propagam-se as significações que fundamentam a existência individual e coletiva; ele é o eixo da relação com o mundo. Pela corporalidade, a criança faz do mundo a extensão de suas experiências. O corpo torna-se um recurso fundamental para fazer e quebrar identidade, precisamente porque, assim como esta última, ele é instável (...) O corpo produz sentidos continuamente e assim participa de forma ativa do espaço social e cultural. $\mathrm{O}$ processo de socialização da experiência corporal é uma constante da condição social da criança (...) oferece a possibilidade de construir-se como ator social. (FINCO, 2015, p. 118) 
Como se percebe, constitui-se num desafio para os profissionais da educação infantil a descolonização de corpos e estéticas marcadas por estereótipos e por uma lógica binária e de hierarquização de gênero (FINCO, 2015), pela ideologia do branqueamento (BENTO, 2002) e pelo mito da democracia racial (FERNANDES, 1965) que permeou e permeia as relações sociais no nosso país.

O choro de Alana analisado a partir das adjetivações recebidas pelo seu cabelo dá pistas sobre esse tenso processo de constituir-se como menina e negra, bem como do reconhecimento de seu corpo a partir da relação com os educadores(as) e demais crianças. As relações estão atravessadas por ambiguidades, hierarquizações e contradições sociais, numa sociedade organizada numa lógica binária.

É importante considerar que, se essas relações não forem problematizadas nos espaços educativos, as crianças vão construir suas identidades achando "natural" pensar os diferentes fenótipos a partir de uma hierarquização, na qual a branquitude torna subalternas as demais identidades, definindo espaços e identidades socialmente válidas e reconhecíveis.

Alana, ao dirigir-se enfaticamente ao Jefferson para dar-lhe ciência de seu saber sobre sua bonitęa, passa a ocupar um espaço de poder como menina negra, no qual sua estética e seu corpo não se submetem a outras estéticas. Um olhar e um corpo que se expandem e não se retraem no espaço e que, na mesma medida, educam outras crianças e adultos.

\section{Considerações finais: Por uma pedagogia e um olhar descolonizadores}

Retomando nossas questões iniciais, podemos afirmar que as meninas negras constroem suas identidades étnico-raciais nas relações sociais com meninos e meninas, a partir de seus cabelos crespos, na medida em que os percebem como características próprias e peculiares de si mesmas.

Nas creches, tal qual em outros tempos e espaços remotos, as meninas negras recebem informações sobre a inadequação de seus corpos e cabelos.

O contexto investigado revelou que as crianças são capazes de se afirmar, resistir e ressignificar as situações nas quais são postas em evidência negativa, considerando seu pertencimento étnico-racial e de gênero.

Esta investigação nos leva à reflexão de que existem espaços de resistência presentes em uma zona de tensão e poder na qual as identidades são constituídas pelas meninas negras, e de que, nesse local, o cabelo crespo e a pele negra se constituem em oposição ao eurocentrismo e etnocentrismo.

Entretanto, um grande desafio que se impõe é o de promover situações nos espaços nos quais as crianças negras possam ampliar as formas de orgulho do pertencimento racial nesses corpos negados, de forma que as diferentes estéticas se imponham no cotidiano das creches.

A investigação revelou que as crianças nos ensinam a transgredir e a inaugurar outras lógicas, quando nos convidam a olhar o mundo sempre como se fosse pela primeira vez, com o estranhamento necessário, e quando, ao mesmo tempo, nos convidam a abraçar o compromisso ético, estético e político 
como adultos brincantes comprometidos com a construção de uma sociedade mais justa entre meninos e meninas, homens e mulheres, brancos(as) e negros(as).

O diálogo com os dados da pesquisa instiga a outros questionamentos, convidando-nos à inversão das lógicas de dominação: o empoderamento de uma menina negra, reconhecendo-a como potência na inauguração de espaços de transgressão, a desconstrução de estereótipos e o combate ao silêncio que propagam o sexismo, o racismo e outras desigualdades socialmente construídas.

\section{Referências}

ABRAMOWICZ, Anete; OLIVEIRA, Fabiana de. As relações étnico-raciais e a sociologia da infância no Brasil: alguns aportes. In: BENTO, Maria Aparecida Silva (Org.). Educação Infantil, igualdade racial e diversidade: aspectos políticos, jurídicos e conceituais. São Paulo: CEERT, 2011.

ARIÈS, P. História social da criança e da família. Rio de Janeiro: Jorge Zahar, 1981

BENTO, Maria Aparecida Silva. Branqueamento e branquitude no Brasil. In: CARONE, Iray; BENTO, Maria Aparecida Silva (Orgs.). Psicologia social do racismo: estudos sobre branquitude e branqueamento no Brasil. Petrópolis: Vozes, 2002, p.5-58.

BRAGA, Aline de Oliveira. "Solta o cabelo": etnografia sobre o cabelo crespo como marcador de identidade étnico-racial entre crianças negras da educação infantil. Dissertação de Mestrado. Faculdade de Educação - UERJ, 2016.

BRAH, Avtar. Diferença, diversidade, diferenciação. In: Cadernos Pagu, v.26, p.329-376, 2006.

BRASIL. Conselho Nacional de Educação. Parecer CNE/CP 3/2004. Diretrizes curriculares nacionais para a educação das relações étnico-raciais e para o ensino de história e cultura afro-brasileira e africana. Brasília, 2004.

CARNEIRO, Sueli. Enegrecer o feminismo: a situação da mulher negra na América Latina a partir de uma perspectiva de gênero. In: ASHOKA EMPREENDEDORES SOCIAIS; TAKANO CIDADANIA (Orgs.). Racismos contemporâneos. Rio de Janeiro: Takano, 2003.

CERISARA, Ana Beatriz. Em busca do ponto de vista das crianças nas pesquisas educacionais: primeiras aproximações. In: SARMENTO, M.J.; CERISARA, A.B. (Orgs.). Crianças e miúdos: perspectivas sociopedagógicas da infância e educação. Porto: ASA Editores, 2004. 
CHAVES, Rosa Silvia Lopes. (In)visibilidade dos cabelos crespos: construção das identidades de meninas negras na creche. Seminário Internacional Fazendo Gênero 11 \& 13th Women's Worlds Congress (Anais Eletrônicos). Florianópolis, 2017. ISSN 2179-510X. Disponível em: http://www.wwc2017.eventos.dype.com.br/resources/anais/1499502535 ARQUIVO TextoCompletoF GRosaChaves2017a.pdf. Acesso em ago./2017.

CONNELL, Robert W.; MESSERSCHMIDT, James W.. Masculinidade hegemônica: repensando o conceito. Estudos feministas, v.21, n.1, p.241-282, mai. 2013. Florianópolis. ISSN 1806-9584. Disponível em: https://periodicos.ufsc.br/index.php/ref/article/view/S0104026X2013000100014/24650. Acesso em set./2017.

CORSARO, William A. Sociologia da infância. 2 ed.. Porto Alegre: Artmed, 2011.

Reprodução interpretativa e cultura de pares. In: MULLER, F.; CARVALHO, A.M.A. (Orgs.). Teoria e prática na pesquisa com crianças: diálogos com William Corsaro. São Paulo: Cortez, 2009.

Entrada no campo, aceitação, e natureza da participação nos estudos etnográficos com crianças pequenas. In: Educação e Sociedade. Sociologia da infância: pesquisas com crianças. Revista de ciência da educação. Campinas. v.26, n.91, mai./ago. 2005.

CRENSHAW, Kimberlé. Documento para o encontro de especialistas em aspectos da discriminação racial relativos ao gênero. In: Estudos feministas. v.10, n.01, Florianopólis, UFSC, 2002.

DELGADO, Ana Cristina Coll; MULLER, Fernanda. Sociologia da infância: pesquisa com crianças. Educação e sociedade. Campinas, vol.26, n.91, p.351-360. 2005.

FANON, Frantz. Pele negra, máscaras brancas. Trad. Renato da Silveira. Salvador: EDUFBA, 2008.

FARIA, Ana Lúcia Goulart de; FINCO, Daniela. Sociologia da infância no Brasil. Campinas: Autores Associados, 2011.

FARIA, Ana Lúcia Goulart de; DEMARTINI, Zeila de B.F.; PRADO, Patrícia Dias. Por uma cultura da infância: metodologias de pesquisa com crianças. Campinas: Autores Associados, 2002.

FARIA, Ana Lúcia Goulart de. Pequena infância, educação e gênero: subsídios para um estado da arte. Cadernos Pagu. Campinas, n.26, jan./jun. 2006. 
FARIA, Ana Lúcia Goulart de; BARREIRO, Alex; MACEDO, Eliana Elias de; SANTIAGO, Flávio; SANTOS, Solange Estanislau dos (Orgs.). Infâncias e pós-colonialismo: pesquisas em busca de pedagogias descolonizadoras. Campinas: Leitura Crítica / Associação de Leitura do Brasil, 2015.

FARIAS, Ana Carolina Batista de Almeida. "Loira você fica muito mais bonita": relações entre crianças de uma EMEI da cidade de São Paulo e as representações étnico-raciais. Dissertação (Mestrado em Educação), Faculdade de Educação da Universidade de São Paulo, São Paulo, 2016.

FERNANDES, Florestan. A integração do negro na sociedade de classes: "O legado da raça branca". Vol.1. São Paulo: Dominus, 1965.

FINCO, Daniela. Educação infantil, espaço de confronto e convívio com as diferenças: análise das interações entre professoras e meninos e meninas que transgridem as fronteiras de gênero. 216 folhas. Tese (Doutorado em Sociologia da Educação). Faculdade de Educação da Universidade de São Paulo, São Paulo, 2010.

Encontro com as diferenças na Educação Infantil: meninos e meninas nas fronteiras de gênero.

Leitura: Teoria \& Prática, Campinas, v.31, n.61, p.169-184, nov. 2013. Disponível em: https://tp.emnuvens.com.br/ltp/article/view/182. Acesso em 15/05/2016.

Gênero, corpo, infância: desafios para educação descolonizadora de meninos e meninas. In: FARIA, Ana Lúcia Goulart de; BARREIRO, Alex; MACEDO, Eliana Elias de; SANTIAGO, Flávio; SANTOS, Solange Estanislau dos (Orgs.). Infâncias e pós-colonialismo: pesquisas em busca de pedagogias descolonizadoras. Campinas: Leitura Crítica / Associação de Leitura do Brasil, 2015.

FINCO, Daniela; OLIVEIRA, Fabiana. A sociologia da pequena infância e a diversidade de gênero e de raça nas instituições de educação infantil. In: FARIA, Ana Lúcia Goulart de; FINCO, Daniela. (Orgs.). Sociologia da Infância no Brasil. Campinas: Autores Associados, 2011. p.60-80.

GOBBI, Márcia. Desenho infantil e oralidade: instrumentos para pesquisas com crianças. In: FARIA, A.L.G. de; DEMARTINI, Z.B.F.; PRADO, P. (Orgs.). Por uma cultura da infância: metodologias de pesquisa com crianças. Campinas: Autores Associados. 2002. p.69-92.

GOMES, Nilma Lino. Corpo e cabelo como ícones de construção da beleza e da identidade negra nos salões étnicos de Belo Horizonte. Tese (Doutorado). Faculdade de Filosofia, Letras e Ciências Humanas da Universidade de São Paulo, 2002(a). 
GOMES, Nilma Lino. Trajetórias escolares, corpo negro e cabelo crespo: reprodução de estereótipos ou ressignificação cultural? Revista brasileira de educação, n.21, p.40-51, set./out./nov. 2002(b). Disponível em: http://www.scielo.br/pdf/rbedu/n21/n21a03. Acesso em 05/12/2016.

Relações étnico-raciais, educação e descolonização dos currículos. Currículo sem fronteiras, v.12, n.1, p.98-109, jan./abr. 2012. Disponível em: www.curriculosemfronteiras.org. Acesso em $02 / 06 / 2017$

Educação, identidade negra e formação de professores/as: um olhar sobre o corpo negro e o cabelo crespo. Educação e pesquisa, São Paulo, v.29, n.1, p.167-182, jan./jun. 2003.

Corpo e cabelo como símbolos da identidade negra. Ação Educativa, 2006. Disponível em: www.acaoeducativa.org.br/.../Corpo-e-cabelo-como-símbolos-da-identidade-negra.pdf. Acesso em $23 / 11 / 2016$

GUIMARÃES, Antonio Sérgio Alfredo. Racismo e antirracismo no Brasil. São Paulo: Editora 34, 1999.

.Preconceito de cor e racismo no Brasil. Rev. Antropol. [online]. 2004, vol.47, n.1, p.9-43. ISSN 0034-7701. Disponível em: http://dx.doi.org/10.1590/S0034-77012004000100001.

Como trabalhar com "raça" em sociologia. Educ. Pesqui. [online]. 2003, vol.29, n.1, p.93-107. ISSN 1517-9702. Disponível em: http://dx.doi.org/10.1590/S1517-97022003000100008.

JENKS, Chris. Investigação Zeitgeist na infância. In: CHRISTENSEN, Pia; ALLISON, James (Orgs.). Investigação com crianças: perspectivas e práticas. Porto, 2005.

MALACHIAS, Rosângela. Cabelo bom. Cabelo ruim. Col. "Percepções da diferença: negros e brancos na escola”. Ministério da Educação, 2005.

MARTINS FILHO, A.J.; PRADO, P. (Orgs.). Das pesquisas com crianças à complexidade da infância. São Paulo: Autores Associados, 2011.

MAUSS, Marcel. Sociologia e antropologia. São Paulo: Cosac Naify, 2003.

OLIVEIRA, F. de; ABRAMOWICZ, A. Infância, raça e "paparicação".Educação em revista. Belo Horizonte, v.26, n.2, p.209-226, ago. 2010. 
OLIVEIRA, Waldete Tristão Farias. Diversidade étnico-racial no currículo da Educação Infantil: o estudo das práticas educativas de uma EMEI da cidade de São Paulo. Tese (Doutorado em Educação). Faculdade de Educação da Universidade de São Paulo. São Paulo, 2017.

Trajetórias de mulheres negras na educação de crianças pequenas no distrito do Jaraguá, em São Paulo: processos diferenciados de formação e de introdução no mercado de trabalho. Dissertação (Mestrado). PUC-SP, 2006.

OSTETTO, Luciana. Encontros e encantamentos na Educação Infantil: partilhando experiências de estágio.Campinas: Papirus, 2000.

RIBEIRO, Djamila. O que é lugar de fala. Belo Horizonte: Letramento / Justificando, 2017.

ROSEMBERG, Fúlvia. Educação para quem?. Ciência e cultura. São Paulo, SBPC, v.12, n.28, p.14661471, dez. 1976.

A criança pequena e o direito à creche no contexto dos debates sobre infância e relações raciais. In: BENTO, Maria Aparecida Silva (Org.). Educação Infantil, igualdade racial e diversidade: aspectos políticos, jurídicos e conceituais. São Paulo: CEERT, 2011. p.10-46.

SARMENTO, Manuel Jacinto. As culturas da infância nas encruzilhadas da segunda modernidade. In: SARMENTO, Manuel Jacinto; CELISARA, Ana Beatriz (Orgs.). Crianças e miúdos: perspectivas sociopedagógicas da infância e educação. Lisboa: ASA Editores, 2004.

Sociologia da infância: correntes e confluências. In: SARMENTO, M. J.; GOUVEA, M. C. S. (Orgs.). Estudos da infância: educação e práticas sociais. Petrópolis: Vozes, 2008. p.17-39.

Estudos da infância e sociedade contemporânea: desafios conceptuais. O social em questão. Rio de Janeiro, PUC-RJ, v.XX, n.21, 2009.

Visibilidade social e estudo da infância. In: VASCONCELLOS, Vera Maria Ramos; SARMENTO, Manuel Jacinto (Orgs). Infância (in)visível. Araraquara / São Paulo: Junqueira \& Marin, 2007. p. 25-49.

SCOTT, Joan. Gênero: uma categoria útil para análise histórica. Educação \& realidade. Porto Alegre, v.20, n.2, p.71-99, jul./dez. 1995. 
SOARES, Natália Fernandes. A investigação participativa no grupo social da infância. In: Currículo sem fronteiras, v.6, n.1, jan./jun. 2006.

Recebido em: 24/02/2018

Aprovado em: 05/04/2018 